\title{
Developing case studies for implementing COST TU1406 Quality Control plan procedure for typical highway bridges
}

Amir Kedar

Kedmor Engineers Ltd, Israel

Sander Sein

Tallinn University of Technology, Tallinn, Estonia

Naida Ademovic

Faculty of Civil Engineering, University of Sarajevo, Sarajevo, Bosnia and Herzegovina

Panagiotis Panetsos

Egnatia Odos AE, Greece

Pavel Ryjáček

Faculty of Civil Engineering, CTU Prague, Department of Steel and Timber Structures, Czech Republic

Amos Duke

Kimron Engineering Ltd., Israel.

Jose C Matos

University of Minho, Institute for Sustainability and Innovation in Structural Engineering (ISISE)

Contacting author: akedar@kedmor.co.il

\section{Abstract}

An extensive work was done by COST TU1406 working groups (WG) 1,2 and 3 for preparing a guidance document for Quality Control Plan (QCP) of road bridges. WG 1, 2 and 3 reports named 'Performance Indicators for Roadway Bridges', 'Performance Goals for Roadway Bridges' and 'Establishment of a quality control plan' are already published. Based on these documents and the work done to-date, a new procedure for implementing the developed guidelines for the preparation of QCP for roadway bridges was developed by WG4 members in order to unify the method used and to validate the outcomes of the developed QCP. At the first stage, a set of common highway bridge prototypes were identified including girder, frame, arch and truss bridges. A database was created where each participating country has identified local bridges for developing of the case studies. Nine out of sixty bridges where selected for the first stage of preparing an example of QCP and the case study reports were compared with an objective to validate the outcomes. A guideline document was prepared with unified instruction on how to develop the national case study per country. The typical case study includes few stages which are defined based on the work done by WG1, 2 and 3. The stages includes data collection, element identification and grouping, defining vulnerable zones, damage processes and failure modes, selecting and evaluating performance indicators (PIs) and calculating key performance indicators (KPIs), establishing demands, creating QCP scenarios and comparing them by spider diagrams. First outcomes of the prototypes case study reports are now being updated to reflect the final version of WG3 report and together with the guidelines document will be distributed among participating countries to enable the benchmarking process for the full set of bridges representing Europe common highway bridge topologies.

Keywords: Bridge maintenance; Quality control plan; Bridge inspection; Case study; Key performance indicator; Failure modes, Lifetime maintenance scenario; 


\section{Introduction}

Standard ISO 2394 [1], which is the basis of most of the national design standards, define fundamental requirements that structures, and structural elements shall be designed, constructed and maintained in such a way that they are suited for their use during the design working life and in an economic way. On the other hand, European Commission Report [2] has addressed that, freight transport is expected to increase significantly by 2030 and most of the proportion will have to be absorbed by roads.

Therefore, COST Action TU1406 has brought together research and practicing community in order to accelerate the establishment of guidelines for implementing performance-based bridge assessment [3]. One of the objectives was to develop guidelines for establishment of QCP for roadway bridges and to develop detailed examples for practicing engineers. Different methodologies for obtaining performance indicators, as well as threshold values are used as the basis for the benchmarking. The basis was already finished during the first three steps of the action, which included establishing the use of Pls (WG1 'Performance indicators'), definition of standardized performance goals (PGs), definition of threshold types to specific KPIs (WG2 'Performance goals') and the preparation of guideline for the establishment of QCP for roadway bridges (WG3 'Establishment of a QCP'). In order to enable the preparation of recommendations for practicing engineers (WG5 'Drafting of guideline/recommendations') WG4 has used the developed guidelines [7] with real bridge case studies and evaluated the suggested methodology. This paper describes the procedure of implementing the QCP in common typology highway bridge case studies. We hereby present the main observations, that were noted during single bridge case studies which were prepared according to WG4 guidelines. In the future, the detailed results of the case studies will be analysed altogether and used for further development of the guidelines. Each case study report will be available in the final report of COST Action TU1406.

\section{Selecting Bridges for case studies}

The first task of WG4 was to collect a set of roadway bridges, belonging to different COST countries and establish a data base which from them case studies will be chosen. The case studies bridges were selected carefully in order to represent correctly the most common topologies of highway bridges in use as selected by COST TU1406 WG3 for implementation of the QC plans. This chapter describes the process of selecting the sample bridges for WG4 case studies.

An inventory bridge ID data table format was prepared, accompanied by detailed guidance document [8]. Both documents were sent to all COST TU1406 participating countries and are available at TU1406 website. Each country representative person sent the data table form filled with data of three typical bridges, defined as candidates for the WG case studies. The three typical bridges were selected by each country according to the following criteria:

1. The bridge must be a common type road bridge.

2. As suggested by TU1406 WG3, three types of bridge typologies were selected [WG3]: Girder bridge (Concrete, Composite), Arch bridge (Concrete, Steel, Masonry) and Frame bridge (Concrete, Steel).

3. One bridge shall be built and maintained by a highway authority, other shall be a bridge built and maintained by concessionaire (as part of PPP, BOT, PFI projects) and one bridge shall be a bridge built and maintained by Municipality.

4. At least one of the bridges shall be located in a natural hazard area.

5. Inspection history for each bridge shall include at least two rounds of existing inspection with one being a principal inspection.

6. For each bridge QC plan based on current national standard should exist.

7. Easy and safe to access for obtaining complementary data. If possible, the bridge selected is intended to be inspected soon

8. A bridge that is included in relevant research project - considered as advantage 
9. A bridge that has existing NDT or monitoring data - considered as advantage

After receiving the complete data tables, nine highway bridges were selected as shown in Figure 1 and Table 1.

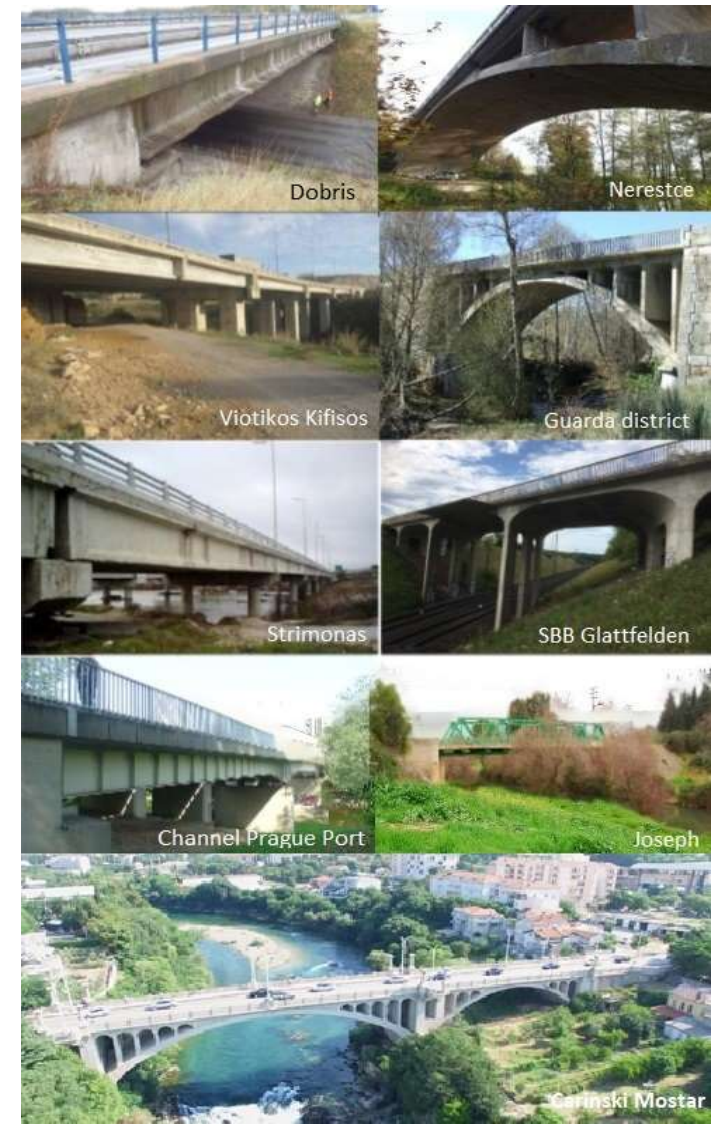

Figure 1. First group of case studies pictures

Table 1. Bridges selected as first group of case studies

\begin{tabular}{lll}
\hline Bridge Name & Type & Country \\
\hline Dobris & Girder & $\begin{array}{l}\text { Czech } \\
\text { Republic }\end{array}$ \\
\hline Viotikos Kifisos & Girder & Greece \\
\hline Strymonas River & Girder & Greece \\
\hline $\begin{array}{l}\text { Channel Prague Port, } \\
\text { Warsaw }\end{array}$ & Girder & Poland \\
\hline Nerestce & Arch & $\begin{array}{l}\text { Czech } \\
\text { Republic }\end{array}$ \\
\hline Carinski Mostar & Arch & $\begin{array}{l}\text { Bosnia and } \\
\text { Herzegovina }\end{array}$ \\
\hline Guarda district & Arch & Portugal \\
\hline SBB Glattfelden & Frame & Switzerland \\
\hline Joseph Bridge & Truss & Israel \\
\hline
\end{tabular}

\section{Implementing the suggested QCP methodology in real bridges}

In order to be able to evaluate correctly the value of the suggested QCP approach [5] a set of nine highway bridges were selected as described. The preparation process for each case study was done in stages, incorporating six pre-defined tasks which were based on the recommendation of TU1406 WG1, WG2, and WG3 [4],[5],[6] as described herein:

1. Collecting bridge Identification data (ID) data - this task includes the preparation/update of a bridge ID/ birth certificate as per the format given in a specific guide published [8]. The information is relying on inventory data (if exist) and additional data acquired on site.

2. Identification of bridge elements - this task includes the preparation of a bridge elements data table using the defined taxonomy of TU1406 [5]. For each element the dimensions and dimension units are documented.

3. Elements grouping and segmentation The bridge elements are grouped together according to different criteria such as geometry, functionality, materials, exposure etc.

4. Identify failure modes - design documentation is used to define possible failure scenarios. for example: rigid body movement (loss of stability), internal mechanism (shear, bending, ...), fatigue, functionality, comfort (to the user), visual appearance (to community), safety (falling parts) etc.

5. Define vulnerable zones - conceptual weaknesses in the specific bridge type are identified. We defined and documented the vulnerable zones on the bridge and correlate them with the relevant failure modes. Documentation includes plan, elevations and sections as needed with marked positions of the zones and the relevant failure mode using pre-defined labels. 
6. Evaluate virgin reliability - for case studies where quantitively approach is selected, the "Virgin" reliability of the bridge is assessed using the prototype or specific bridge historical design data. Simplified or more precise models can be used. In Guarda district arch bridge [9] in Portugal the calculated virgin reliability of the bridge was calculated for the simple supported arch top section by using Monte-Carlo simulation.

Following the preparation stage, a site work stage marked as task no. 7 [7] was performed. This task includes the bridge inspection and complementary non-destructive and destructive tests (depend on the case study). For Strimonas river bridge [7], onsite temporary dynamic monitoring was also conducted in order to find the actual change in the modes of the bridge and compare with previous measurements and theoretical values. The on-site visual bridge inspections were done taking into account the specific recommendations defined for each bridge prototype and the previously defined vulnerable zones and identified failure modes. Possible hidden defects/damages were also investigated. The damages were identified and compared with previous inspections results. Documentation was done using TU1406 WG3 recommendations [5]. Following the inspection, the need for update of the failure modes and vulnerable zones data from tasks 4 and 5 was checked.

Once the site work stage was finished, the third stage of processing the results was carried out with additional eight pre-defined tasks marked as task $(8-12)$ which include the following:

8. Identification of the existing damage processes - the damage processes on each bridge were identified using the information collected during the bridge inspections and the predefined proposed damage processes as per TU1406 WG3 report [5].

9. Selecting PIs for the bridge and connecting with KPIs - appropriate PIs were selected and connected to relevant KPIs [4] considering the observations and the damage processes identified.

10. Evaluating the PIs - Relevant PIs were selected for the bridge prototype and for the specific bridge considering the specific scheme, materials and possible sudden events. The PIs were evaluated using predefined thresholds as per the owner demands (normally defined in the national professional guidelines) or the expert team decision.

11. Assessment of KPIs - Qualitative assessment of the resistance reduction for each case study was based on the observed damages. The evaluation of the reliability and safety KPIs was based on simple "Engineering Judgment" in most of the case studies, however it is possible also to use other agreed methods such as complex Bayesian Nets or others. The suggested WG3 QCP protocol [5] was used for performance evaluation and derivation of the KPIs from PIs and all KPIs were normalized. The Cost KPI was scaled based on the maximum yearly cost of all scenarios.

12. Deterioration processes and timing (time to failure) - Following the evaluation of the different PIs and KPIs, we assessed the remaining service life (i.e. the point in time at which Reliability or Safety will reach the defined threshold value or unacceptable return period for a failure without any intervention) for each component. This task included the assessment of the speed of the identified active deterioration processes and damage forecast. For each documented damage on specific component we indicated the relevant damage process and estimated the time to failure. The results were documented on the PIs/KPIs evaluation table prepared for each bridge (figure 3). In some of the case studies the assessment was based on expert judgment while in others deterioration models were used. 
The above tasks marked 1 to 12 were defined as 'static' while the next stage which includes tasks 13 to 15 involving the developing of different maintenance scenarios were defined as 'Dynamic' [5] as they depend on decision taken through the process which can repeatedly change in order to create different scenarios. Tasks 13 to 15 were depending on the specific scenarios developed for each bridge (normally two to three scenarios).

13. Preparing Inspection/tests/monitoring plan - For the reference scenario and for other preventive scenarios the inspections type and intervals were defined with the associated cost (as annual cost). Than the future type and timing for nondestructive/destructive (NDT/DT) testing and monitoring with the related costs were evaluated. The associated costs were taken as part of the yearly cost for each scenario.

14. Defining maintenance and other Interventions plan scenarios - several maintenance scenarios with targeted reliability and safety over time were defined for each bridge. The time frame (for how many years) and the cost of the different interventions per each scenario over time were estimated based on the experience of the team and the actual prices at each country. The costs were combined with the estimated Inspection/testing/monitoring costs (task 13). The function of decrease of Reliability and Safety was defined for each bridge and for each scenario a graph of the four KPIs Reliability (R), Availability (A), Safety (S) and Cost (C) over time was plotted using an excel 'Spidertool' developed by WG3. All KPIs were normalized (range 1 to 5).

15. Comparing scenarios - A Spider diagrams of net present KPI for all scenarios was plotted for a single point in time and the area of the spider was compared. In some bridges few spiders were used for different time points or a continues process using 3D volume shape of the KPIs over time was used. In such case the volume of the 3D shapes created for the different scenarios was compared.

\section{Vulnerable zones and failure modes}

As part of the described stages (task no. 5) the vulnerable zones for each bridge were carefully selected according to the visual observation and experiences of the inspector (Figure 2). This is one of the major changes from the current common inspection procedure used in most of COST TU1406 participating countries. The advantage of this approach is mainly by focusing the attention of the inspector to the more important zones influencing the reliability and safety of the bridge and saving time and efforts. For a bridge with historical data, the work was done in the office prior to the onsite work and was updated if additional relevant data was gathered during the inspection. In case of a bridge without previous data, it was necessary to identify and map the vulnerable zones during the onsite work. Special attention was given to identifying conceptual weaknesses, vulnerable zones related to the superstructure, vulnerable zones related to substructure, damages related to equipment and understanding if there are hidden defects/damages. The design documentation combined with vulnerable zone identification and knowledge of the high bending moments or shear forces was used to define the failure scenarios. For each scenario we identify the possible failure modes, for example: rigid body movement (loss of stability), internal mechanism (shear, bending, ...), fatigue, functionality, comfort (to the user), visual appearance (to community), safety (falling parts) etc.

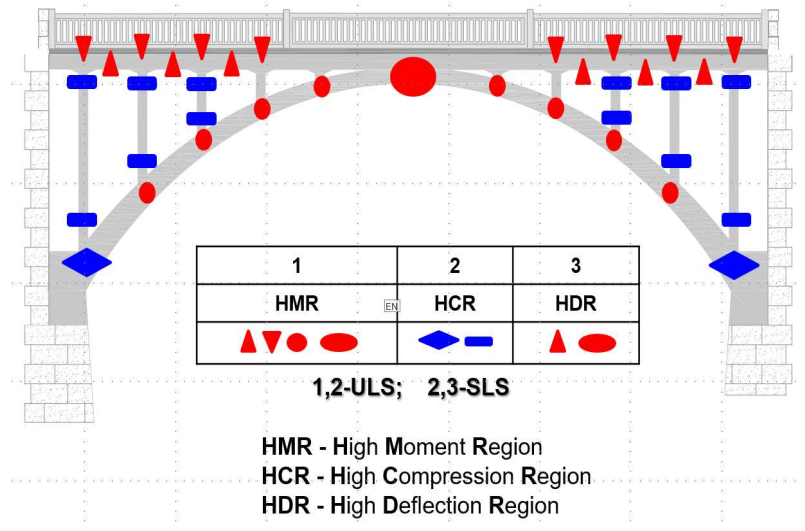

Figure 2. Vulnerable zones of Guarda arch bridge[7] 


\begin{tabular}{|c|c|c|c|c|c|c|c|c|c|c|c|c|c|c|}
\hline \multirow{2}{*}{ 壱 } & \multirow{2}{*}{ 홍 } & \multirow{2}{*}{ Component } & \multirow{2}{*}{ Material } & \multirow{2}{*}{$\begin{array}{c}\text { Design \& } \\
\text { Construction }\end{array}$} & \multirow{2}{*}{ Failure mode } & \multirow{2}{*}{$\begin{array}{l}\text { Location/ } \\
\text { Position }\end{array}$} & \multirow{2}{*}{ Damage /Observation } & \multirow{2}{*}{$\begin{array}{l}\text { Damage } \\
\text { process }\end{array}$} & \multirow{2}{*}{ KPI } & \multirow{2}{*}{\multicolumn{2}{|c|}{$\begin{array}{c}\text { Performance } \\
\text { Indicator } \\
\text { component } \\
\text { level }\end{array}$}} & \multicolumn{2}{|c|}{$\begin{array}{c}\text { Performance } \\
\text { value }\end{array}$} & \multirow{2}{*}{$\begin{array}{c}\text { Estimated } \\
\text { failure } \\
\text { time } \\
\text { [years] } \\
\end{array}$} \\
\hline & & & & & & & & & & & & R & s & \\
\hline \multirow{16}{*}{ ТВ } & \multirow{16}{*}{ 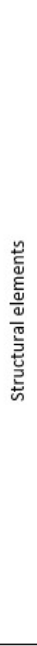 } & \multirow{9}{*}{$\begin{array}{l}\text { Main } \\
\text { Trusses }\end{array}$} & \multirow{9}{*}{ Steel } & \multirow{9}{*}{1954} & \multirow{4}{*}{$\begin{array}{c}\text { Truss } \\
\text { Bending } \\
\text { failure mode }\end{array}$} & \multirow{2}{*}{$\begin{array}{c}\text { Upper chord } \\
\text { compression } \\
\text { zone } \\
\end{array}$} & Corroded plates & Corrosion & \multirow{12}{*}{$\begin{array}{l}\text { Reliability } \\
\text { (Structure } \\
\text { safety) }\end{array}$} & 2.3 & \multirow{9}{*}{4.1} & \multirow{16}{*}{4.1} & \multirow{16}{*}{2.1} & 40 \\
\hline & & & & & & & Corroded rivet & Corrosion & & 2.3 & & & & 40 \\
\hline & & & & & & \multirow{2}{*}{$\begin{array}{l}\text { Lower chord } \\
\text { tension zone }\end{array}$} & Corroded plates & Corrosion & & 2.3 & & & & 40 \\
\hline & & & & & & & Corroded rivet & Corrosion & & 2.3 & & & & 40 \\
\hline & & & & & \multirow{3}{*}{$\begin{array}{l}\text { Truss Shear } \\
\text { failure mode }\end{array}$} & \multirow{3}{*}{ Diagonals } & Corroded plates & Corrosion & & 2.3 & & & & 40 \\
\hline & & & & & & & Corroded rivet & Corrosion & & 2.3 & & & & 40 \\
\hline & & & & & & & Accidental damage & Impact & & 2.0 & & & & 20(?) \\
\hline & & & & & Global & Connection of & sheared rivet & Fatigue & & 4.1 & & & & 15 \\
\hline & & & & & $\begin{array}{l}\text { buckling of } \\
\text { truss upper } \\
\text { chord }\end{array}$ & $\begin{array}{l}\text { truss verticals } \\
\text { with deck cross } \\
\text { girder }\end{array}$ & $\begin{array}{c}\text { Out of plane } \\
\text { movement of lower } \\
\text { connection plate }\end{array}$ & Fatigue & & 4.1 & & & & 20 \\
\hline & & & & & Bending & $\begin{array}{l}\text { High sagging } \\
\text { area }\end{array}$ & $\begin{array}{l}\text { Shear connection with } \\
\text { deck corroded }\end{array}$ & Corrosion & & 2.1 & & & & 30 \\
\hline & & $\begin{array}{l}\text { Cross } \\
\text { girders }\end{array}$ & Steel & 1954 & $\begin{array}{c}\text { web plate } \\
\text { buckling }\end{array}$ & $\begin{array}{c}\text { Bearing area } \\
\text { over main truss }\end{array}$ & $\begin{array}{c}\text { Rivets are partially } \\
\text { sheared }\end{array}$ & Fatigue & & 4.1 & 4.1 & & & 20 \\
\hline & & & & & Bending & Along the girder & Corroded rivet & Corrosion & & 2.1 & & & & 40 \\
\hline & & & & 1954 & Bending & HMS/bottom & delamination & Corrosion & Reliability & 2.1 & 2.1 & & & 30 \\
\hline & & Deck slab & $\begin{array}{l}\text { Reinforced } \\
\text { concrete }\end{array}$ & 1954 & $\begin{array}{l}\begin{array}{l}\text { Falling } \\
\text { chunks }\end{array} \\
\end{array}$ & bottom & Spalling & Corrosion & $\begin{array}{l}\text { Safety (Life } \\
\text { and limb) }\end{array}$ & 2.1 & 2.1 & & & 30 \\
\hline & & & & 1954 & Bending & $\mathrm{HMH}$ & Efflorescence & Leaching & (Symptom) & (2.1) & & & & \\
\hline & & Bearings & Steel & 1954 & $\begin{array}{l}\text { Bearing } \\
\text { Failure }\end{array}$ & $\begin{array}{l}\text { Abutment } 1 \\
\text { (west) }\end{array}$ & Corrosion & Corrosion & Reliability & 2.0 & 4.0 & & & 40 \\
\hline
\end{tabular}

Figure 3 Bridge PI/KPI data structure example [7]

\section{Pls and KPIs in use}

The goal of COST TU1406 WG1 was to make a database of performance indicators. PI measures the fitness for purpose of a bridge and it is actually interpreting the impact of different processes on the bridge performance, opposed to observations which are just stating "the fact". However, PI go together with the observations as this is an essential part during the assessment of the bridge and the preparation of the quality control plan. The final work of WG1 was a list of 385 terms, grouped in 11 clusters from defects to rating and loads [4]. The further work was conducted by the WG3 which suggested four categories which are in the framework for the establishment of the QCPs: Design \& Construction, Observations, Damage Processes and their symptoms [5]. Further, observable symptoms are correlated with potential damage processes leading to certain PIs. In the bridges case studies most of the Pls that were observed and assessed were obtained through the observation and identification of different defects for example: concrete deterioration and the reinforcement corrosion, defects of expansion joints, deformations, steel corrosion, waterproofing defects, bearings damage, cracks, delamination, spalling, displacement, deformation, vibration, oscillation. Then, according to those observations and together with the predefined vulnerable zones which were also modified on site in some cases the potential failure modes of the bridge were identified. In order to define the state of the bridge, non-destructive and destructive testing were performed in order to obtain as much as information regarding the (remaining) capacity of the structure. In this sense compressive strength of concrete was tested, alkali-silica reaction, carbonation, freezing resistance, dynamic modes testing of superstructure and so on.

The next step was derivation of the KPIs from the PIs. The KPIs that were evaluated are reliability, availability, safety and evaluation of life time cost. This can be done in several ways either by using the 'Engineering Judgement' or for reliability KPI performing a calculation of the current $\beta$ value based on resistance reduction curves [5] or by using other agreed method like Bayesian Nets.

The definition of the elaborated KPIs in use are:

- Reliability is the probability that a bridge will be fit for purpose during its service life. It is the complement to the probability of structural failure (safety), operational failure (serviceability) or any other failure mode.

- Availability is the proportion of time a bridge is open for service.

- Safety is the situation of life and limb being protected from harm during the service life 
of a bridge.

- Cost is related to minimizing the long-term cost of maintenance activities over the service life of a bridge.

In most of the cases KPIs are determined in a qualitative/empirical manner, in accordance with best practice knowledge of the research team and experiences with bridge inspection, while in a few, more sophisticated deterministic (e.g. safety factor) or probabilistic methods are used to quantitively determine the reliability performance of the bridge. For the last, the accurate measurement of the structural loss is a prerequisite, along with its variance. All KPIs were normalized in the scale from 1 to 5 ( 1 the best to 5 the worst condition) in accordance with the Net Present Value (NPV) (see Figure 4) in the sense that the future expenditures are discounted to present. This was done in order for reduce the KPIs to the same scale as for any time instance, the normalization is performed i.e. the NPV is divided with the NPV calculated if all KPIs were equal to one over the whole investigation period. These values can be regarded as "average" long term KPIs. The decision, which maintenance strategy is to be chosen based on the "average" long term KPIs [6].

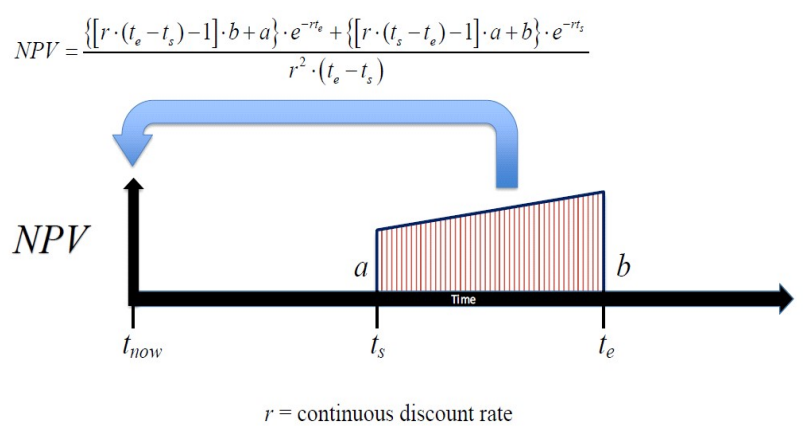

Figure 4. Evaluation of the net present value for time dependent KPIs [5]

\section{Comparing maintenance scenarios}

For each case study bridge two or three life time cycle approaches (reference and preventive) were conducted. I all scenarios we evaluate the value of the above mentioned KPIs for the considered bridge over the following 70 to 100 years (depend on the case). The 'Reference' approach considers reactive maintenance with lack of any planned repairs except of very basic ones. In this scenario we intervene only after severe and extensive deterioration/damage takes place. In the 'preventive' approach, we consider a set of planned repairs during the bridge life time cycle. These are planned in order to prevent further defect development and overall damage to the structure. In that case, we preferred to spend in advance in order to protect or to repair when the damage/deterioration is still limited and does not affect too much the reliability of the bridge.

Following the preparation of the combined interventions and inspections/testing plan with the related costs estimated for the scenarios QCP, it is important to define the function of decrease of the KPIs (Reliability, Safety, Availability and Cost) over time and prepare the time dependent graphs for the KPIs (Figure 5). Usually in most of the case studies, by the absence of a well-documented deterioration model, the rate of the Reliability decay in time, from a lower score today to a higher future score, was empirically/arbitrary chosen as linear or multilinear (see figure 5).

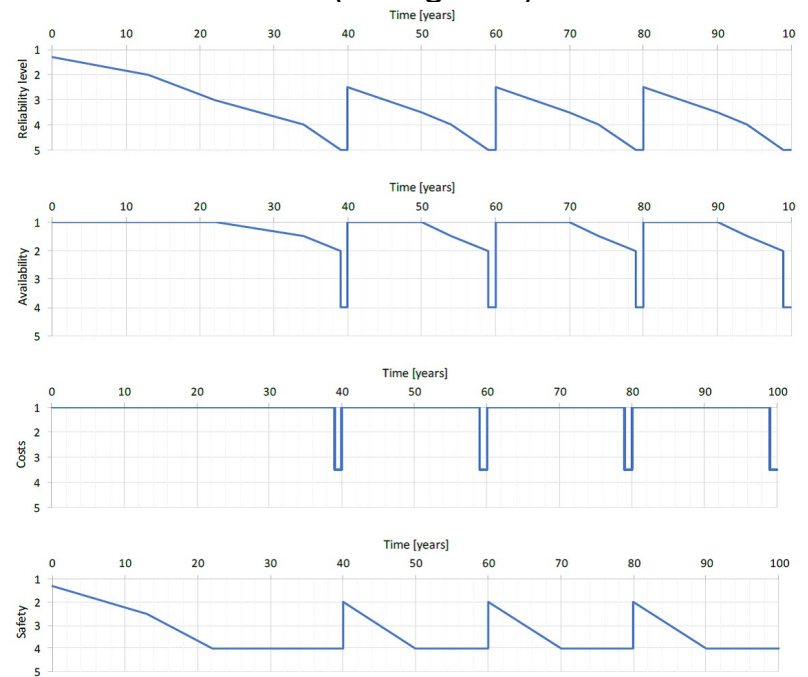

Figure 5. Normalized KPIs over time [7]

As long as the Reliability performance fluctuation of the bridge was defined/charted over time, then availability and safety were easily defined, as they are depended on the first. The same is true for KPI 'Cost', which is the yearly maintenance expenses fluctuation versus time. In most of the case studies the 'Cost' included the major interventions such as structural strengthening, deep/extensive repairs, partial replacements (bearings, expansion joints, pavement, safety barriers), as well as their repetitions in the total remaining life of the bridge. 
The KPIs can be conveniently visualized using a 'Spider net diagram' (Figure 6). Here, each of the KPIs are given on a separate axis. A comparison of the two considered approaches is based on the area of each scenario.

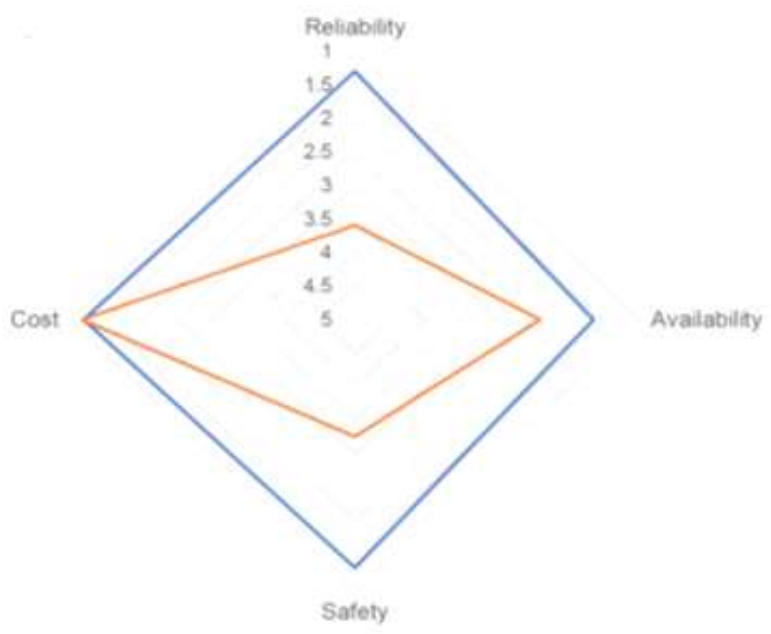

Figure 6. Example of spider diagram for Reference (in orange) and Preventive (in Blue) scenarios [7]

Additionally, when development of KPIs over time is of interest, the time axis can be appended orthogonally on the plane of the diagram. In this manner, the 'performance tube' can be generated [5] (Figure 7). However, in the first group of case studies it was not implemented.

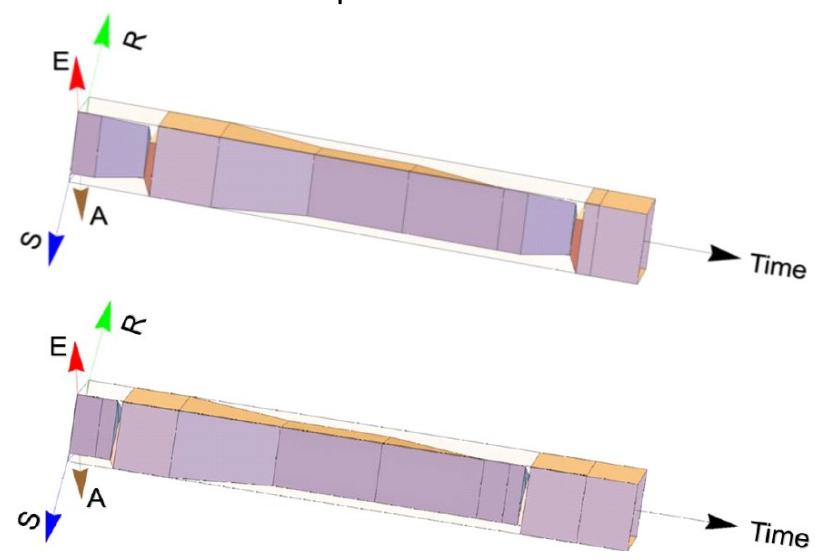

Figure 7. Example of 3D spider TUBE diagram [5]

Additional way of comparing the maintenance scenarios in terms of the evolution of the four KPIs along the total remaining life of the bridge (Figure 5) [7] can be done by comparing 'average' spider diagrams (representing the average KPI scores along the examined remaining life) for each alternative, or by comparing the net present values of the costs associated to each alternative. A Super
KPI (SKPI) was defined in Strimonas river case study, measuring the cumulative score of the bridge in all four KPIs. This SKPI can be calculated by measuring the volume of the full tetragon, that the individual annual scores of the $4 \mathrm{KPIs}$ shape for each year of the remaining life of the bridge. This SKPI is calculated for both the reference and the preventive strategies. Then the scenario with the lower volume, is preferred as it is associated to the strategy that keeps the performance of the bridge in higher level for the remaining life, as in figure 8.

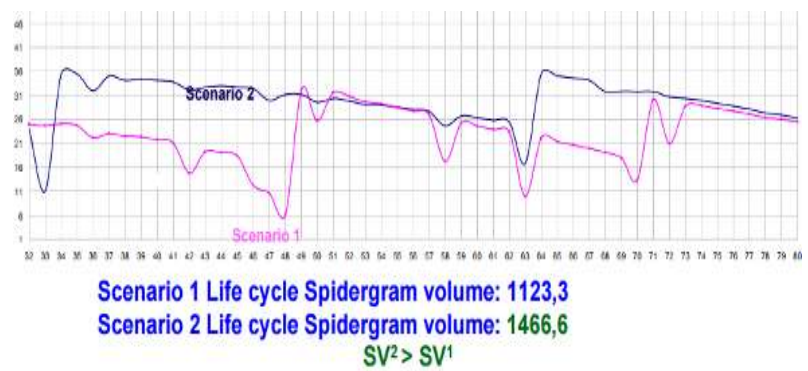

Figure 8. Comparison of the Spidergram life cycle volume for two scenarios [7]

\section{Discussion and future view}

Nine bridge case studies have been prepared as part of the first stage of TU1406 WG4 work. The amount of the site work involved with the preparation of the suggested bridge QCP [5] do not differ much from the current common practice in most of the countries. However, for the preparation and analysis of the bridge inspection result a higher engineering knowledge is needed. This should be accompanied by the use of a more qualified engineers as bridge inspectors, it is not a work suitable for technicians. Some of the preparation work like calculating 'virgin reliability' or preparing vulnerable zones schemes, are onetime effort which should be done by qualified bridge engineers and should be stored in BMS database to be used by the inspectors.

To date, the first nine case studies demonstrate that the suggested methodology is flexible enough, so one can implement part of it or all of it with different level of theoretical models to be used (e.g. use of 'expert judgment' vs. $\beta$ value or factor of safety (FoS) reduction calculations or use of 'expert judgment' vs. deterioration model). It is the bridge owner who will decide how detailed he is willing to go with the theoretical background to be used. 
Most of the work was done using simple computer tools and can easily be implemented as part of a modern BMS.

In overall, each case study was done using the common 'local' practice at each country. When composing the QCP scenarios, local knowledge with the associated costs was used. However, the KPIs in use and the 'Spidergram' created for all, are the same. Some basic variables and calculation models should still be additionally defined by each country.

Based on the experience gained and the first conclusions, and in order to be able to unify the method as much as possible, we prepared 'Guidelines for preparation of a case study' [7]. The guidelines are now being used with the second group of bridge case studies. The results of all case studies will be analysed soon and the conclusion will be documented in WG4 final report intended to be published in the $1^{\text {st }}$ quarter of 2019. All documents can be downloaded from https://www.tu1406.eu/.

\section{References}

[1] ISO (International Organization for Standardization). General principles on reliability of structures. ISO 2394. 2015.

[2] Capros P, Mantzos L, Papandreou V, Tasios $\mathrm{N}$. European energy and transport-trends to 2030-update 2007. European Commission, Directorate-General for Energy and Transport, Institute of Communication and Computer Systems of the National Technical University of Athens. 2008 Apr 8.

[3] European Cooperation in Science and Technology. Memorandum of Understanding for COST Action TU1406. COST, 2014.

[4] Strauss, A.; Mandić Ivanković, A.; Matos, J. C.; Casas, J. R. (2016). COST Action, TU 1406, WG1, Technical Report, Performance Indicators for Roadway Bridges of Cost Action TU1406, ISBN: 978-3-900932-41-1.

[5] Hajdin, R.; Kušar, M.; Mašović, S., Linneberg, P.; Amado, J.; Tanasić, N.; Ademović, N.; Costa, C.; Marić, M.; Almeida, J.; Galvão, N.;
Sein, S.; Zanini, M.; Pendergast, L., (2018) COST Action, TU 1406, WG3 Technical Report Establishment of a Quality Control Plan, ISBN: 978-86-7518-200-9.

[6] Stipanovic, I.; Chatzi, E.; Limonggelli, M.; Gavin, K.; Allah Bukhsh, Z.; Skaric Palic, S.; Xenidis, Y.; Imam, B. ; Anzlin, A.; Zanini, M.; Klanker, G.; Hoj, N.; Ademovic, N. (2017), Performance Goals for roadway bridges of COST TU1406 (WG2 Tehnical Report), s.I.: COST TU1406. ISBN: 978-3-900932-41-1.

[7] Kedar, A.; Sein, S.; Panetsos, P.; Ademović, N.; Duke, A.; Ryjacek P. (2018) COST TU1406, WG4 Technical Report Guidelines for Preparation of a Case study, in print, TU1406 Website.

[8] Duke, A; Kedar, A; (2017) COST TU1406, WG4 Guide for documenting bridges data, TU1406 Website.

[9] Kedar, A.; Sein, S.; Panetsos, P.; Ademović, N.; Duke, A.; Ryjacek P. (2018) COST TU1406, WG4 Final Technical Report, in preparation. 